\title{
The Influence of Affective Factors in Second Language Acquisition on Foreign Language Teaching
}

\author{
Yanyan Bao, Shuzhen Liu \\ Ningbo University of Technology, Ningbo, China \\ Email: 752046921@qq.com
}

How to cite this paper: Bao, Y. Y., \& Liu, S. Z. (2021). The Influence of Affective Factors in Second Language Acquisition on Foreign Language Teaching. Open Journal of Social Sciences, 9, 463-470. https://doi.org/10.4236/jss.2021.93030

Received: March 5, 2021

Accepted: March 28, 2021

Published: March 31, 2021

Copyright ( 2021 by author(s) and Scientific Research Publishing Inc. This work is licensed under the Creative Commons Attribution International License (CC BY 4.0).

http://creativecommons.org/licenses/by/4.0/

\begin{abstract}
Along with the development of humanistic psychology, the affective factors in education are gaining more and more importance. The paper introduces three major affective factors in second language acquisition, which are self-esteem, motivation and anxiety. With the expectation to play the positive role of affective factors in second language acquisition and diminish its negative influences on education, and exert the intuitive subjectivity to study, this paper analyses its application on teaching from the perspective of teachers, as well as its implication on studying from the students' perspective.
\end{abstract}

\section{Keywords}

Affective Factors, Second Language Acquisition, Foreign Language Teaching

\section{Introduction}

For years, second language learners have been influenced by numerous factors while studying the second language, like age, society, environment and so on, among which, affective factors are of great significance. The budding field of affective factors eagerly made connections between psychological personality constructs and second language acquisition (SLA), and offered fruitful implications and applications to classroom teaching methodology (Douglas, 2014: p. 143). Affect means emotion or feeling. Affective factors include the learners' individual factors, the affect between the learners and that between the learners and the teachers. As for the learners' individual factors, it consists of self-esteem, inhibition, anxiety, personality, motivation, attitude, and so on. It is undoubted that the learners are limited by these complex psychological factors. According to Carl Ransom Rogers, American humanistic psychologist, cognition should be 
integrated with affect in order to emphasize the importance of the comprehensive development of human being (Rogers, 1950). Along with the development of humanistic psychology, the affective factors in education are gaining more and more importance.

\section{Literature Review}

Early in 1977, Dulay and Burt first propounded that affect factors can filter language input. In the 1980s, Krashen proposed "Affective Filter Hypothesis" (Krashen, 1985), which demonstrates the learner's motivation, attitude, anxiety and self-esteem are the major affective factors which influence SLA. These factors, like a filter, can promote or impede language input. If the second language learner has strong self-esteem, clear study purpose and moderate anxiety, they will have much more language input, which means the "affective filter" plays a weaker role.

According to Stern, affective factors played the same significant role compared with cognitive factors in SLA (Stern, 1983).

Since late 1990s, studies on affective factors have moved up rapidly. For example, in Affect in Language Learning, J. Arnold and H. Arnold explores affective factors from the perspective of the students, teachers and teaching. It expounds the influences of affective factors in second language learning on foreign language teaching,

In China, studies in this field also keep progressing, such as Individual Affective Factors in SLA and Foreign Language Teaching (Yi, 2008), Implication of Affective Factors in SLA on Foreign Language Teaching (Zhang, 2011), The Influence of affective Factors in SLA on Foreign Languages Teaching (Wu, 2008) and so on.

\section{Affective Factors in SLA}

\subsection{Self-Esteem}

According to Rubio, self-esteem refers to "a psychological and social phenomenon in which an individual evaluates his/her competence and own self according to [a set of] values" (Rubio, 2007: p. 5). Self-esteem is so important that no cognitive or affective activity can be implemented without a certain degree of selfconfidence, or belief in your self that you are able to perform an activity successfully. In order to cognize the world in a maturer perspective of view, a person should know him/herself, accept him/herself and then reflect on his/her own interactions with others. Self-esteem varies based on different situations, it can be classified into three levels: global self-esteem, situational self-esteem and task self-esteem.

For global self-esteem, it is relatively stable, especially in a mature adult, refers to the general evaluations that one makes along with time, on variable situations. Situational self-esteem, also called specific self-esteem, means that one apprise him/herself at different situations, like job, education, home, study, and so on. 
Task self-esteem, often correlated to specific tasks, refers to one's self-evaluation of a particular aspect of the process, like speaking, writing, or a specific classroom activity (Douglas, 2014: p. 144).

For learners, especially second language learners, self-esteem plays a quite significant role, because they are deprived of the discourse competence of their own native language, or, their most fluent way of expression. They may feel vulnerable when being exposed to an atmosphere that only an unfamiliar language is being spoken.

For the learners who have stronger self-esteem, they are more confident, which is more helpful to language learning. Learners who have strong self-esteem will be less anxious and more motivated to learn language. They will be more active in class and make efforts to seize each opportunity to learn and apply the language. At the same time, the experience will enhance people's self-confidence. However, students who lack of self-confidence may be anxious when he/she is in a specific communicative situation or under a specific task. Their subjective initiative may be too low to communicate in the target language. Students' low self-esteem may pose a formidable barrier for them to participate in the classroom activity, to speak the target language. This situation may be increasingly worse, students will lose the interest in learning a new language. As a result, in the learning atmosphere that self-esteem can be increased, the learners' potential will be inspired to the large extent.

\subsection{Motivation}

Motivation refers to the driving force from outside. In psychology, motivation means the internal process that people are stimulated to take certain actions to meet certain needs. In language learning, motivation is the learners' desire and impulse to learn language, providing power and impetus to the learners. There are also various definitions of motivation. From a behavioral perspective, motivation means that people are anticipating the reward, but from the perspective of constructivist, motivation emphasizes social context as well as individual personal choice (Douglas, 2014: p. 159).

Arnold and Brown divide motivation into two types: extrinsic motivation and intrinsic motivation (Arnold \& Douglas, 2000). Extrinsic motivation comes from the desire to win awards or avoid punishment. It is from the outside, related to money, awards, prizes, grades, and appraises from the outside world. For example, considering the importance of extrinsic motivation, some teachers or parents may make promise to give some rewards to their students or children. To cite the author's own experience as an example, when it was the time to take an extremely important examination in China, which was the college entrance examination (also called Chinese gaokao), the author's parents promised her to buy laptop and a new phone to make her more motivated to prepare the examination, and to be honest, it did motivate the author to some extent. This is a widespread phenomenon all over the world. 
Intrinsic motivation, on the other hand, refers to expending effort "for which there is no apparent reward except the activity itself... and not because it leads to an extrinsic rewards." (Deci, 1975: p. 23). Intrinsic motivation is related to people's internal needs, or the internally rewarding consequences, like the feelings of achievement, of competence and the self-determination. According to Maslow, the intrinsic motivation is more important than the extrinsic motivation, because from his perspective, people's need can be ranked as fundamental physical necessities, then community, security, identity, self-esteem, and then self-actualization (Maslow, 1943). In this pyramid-shape hierarchy of needs, the physical necessities are at the bottom, while the self-actualization is at the top. It is the natural order that people push themselves to higher level of performance.

Motivation is one of the most powerful affective variables in accounting for the success or failure of virtually any complex task. It can direct the way for the learners. But which one is more important? Extrinsic motivation or intrinsic motivation? Extrinsic motivation is helpful to learn, but intrinsic motivation is more important to learn language than extrinsic one, especially for the long run. For example, students who have extrinsic motivation may focus on the rewards too much more, than on the task itself. While students who have the intrinsic motivation may pay more attention to the accomplish of the task, which is more helpful for them to learn the new thing, especially language. They will be more persistent and more perseverant, have the determination to finish the specific task.

\subsection{Anxiety}

Anxiety is almost the biggest affective obstacle in language learning. It is closely related to negative affective experience, such as tension, sadness, unease and so on. In language learning, anxiety mainly refers to the learners' fearfulness and uneasiness when they are supposed to express in a foreign language. Language anxiety is inversely proportional to language acquisition: the less anxious, the more acquisition, or the more anxious, the less acquisition. Besides, anxiety is also inversely proportional to academic result, self-esteem, oral and written competence, as well as self-confidence.

On the other hand, during growth, children gradually learn to identify themselves from other people, at the same time, take actions to protect themselves when necessary. One form of the protection is to avoid all the words and behaviors that may endanger themselves, which is called inhibition. In general, the inhibition level of young children is low, so they can take actively part in the activities in class. While, as they grow elder and elder, the inhibition level will become higher and higher. They are too afraid of being criticized or laughed by other people to say any words. As a consequence, high inhibition level cause bad result in language learning.

Besides the three factors mentioned above, affective factors also include empathy, risk taking, outside affective factors, the relationship between the students 
and the teacher, and that between the learners themselves, etc.

\section{Application of Affective Factors in SLA on Teaching}

\subsection{To Build Students' Self-Confidence}

In China, there is a very popular proverb: self-confidence is half of success. In foreign language teaching, the teachers should make great efforts to build the students' self-confidence.

As a second language (L2) learner for so many years, the author has a deep understanding on the importance of self-esteem, or self-confidence in learning the language. When the author was in middle-school, at the beginning of learning a new language, she did care about whether she made mistakes in saying the language. Sometimes, in order to avoid potential embarrassment, the L2 learners will refuse to express themselves. These kinds of students may be negative in classes. Under these circumstances, the teachers' praise and encouragement play a very important role.

In order to build students' self-confidence, teachers can help the students to list their own strengths, of what they know or what they have already accomplished so far in the course. In this way, students can have a clear mind in what they have already learned, self-confidence can be built in this way. Moreover, Teachers can also tell the students explicitly that you do indeed believe in them, both verbally and nonverbally. Teachers' attitudes do count in the students learning, especially in learning an unfamiliar language. Furthermore, if the students made some mistakes, the teacher should correct them in an appropriate way, or the students may feel belittled. Teachers can praise the students for good guesses, correct only selected errors, preferably just those that interfere with learning. Do not always give explanations of errors. In addition, if the students can not achieve ideal results, the teacher should help them to address the problem and set the goal for the next phase (Douglas, 2014: p. 136).

\subsection{To Stimulate Students' Motivation}

Learners' motivation to study can determine their effort. Each kind of motivation can promote language learning. The learner's motivation and their language learning are mutually influenced. As a result, during the process of language teaching, the teacher should emphasize the importance of students' motivation.

To help the students develop intrinsic motivation, the teachers can remind them about the rewards for learning English. For example, for students who plan to find a job related to the target language, the teacher should help them to realize the significance of the language in their future career. The teacher can also invite some famous foreign scholars speaking the target language to deliver speech in the school. And also, different kinds of examinations can stimulate the students' motivation in some aspects. The teachers can play down the final examination in favor of helping students to see rewards for themselves beyond the final exam. 
Moreover, teachers can encourage or direct the students to go beyond the classroom goals, get them to make specific commitments at home to study the language, or have them make a lists of what they will accomplish on their own in a particular week or month. Teachers can also give students "extra credit" work (Douglas, 2014: p. 136).

On the other side, in order not to decrease the students' motivation, the teachers should avoid doing the following things: things that make students feel unpleasant, things that interfere with the students to set goals for themselves, assigning tasks that students feel incapable of accomplishing, and things that disgrace the students.

In addition, language learning is not only to learn the language itself, but also the culture related to it. In language classes, the teacher should introduce the culture of countries that speak the target language, which can attract the students, to get them more motivated to learn the language.

\subsection{To Help Students Lower Anxiety}

The students' anxiety cannot be eliminated unless they feel relaxed and comfortable in class. The teacher should know the students, not only their proficiency level, but also their characters or personality types. The teacher can apply with situational teaching method, or create some games to make students feel relaxed. For example, the teacher can play guessing games and communication games, sing songs or do role plays. In this way, their anxiety can be lowered and they will feel relaxed. Teachers can laugh with the students, have them share anxiety or fear in groups.

If possible, the teacher can set different goals for the students based on their various proficiency levels. If the students aware they have made some progress, they will be more motivated and inclined to learn language.

Furthermore, teachers can praise students for making sincere efforts to try out language. Compliment is helpful to lower the students' anxiety and inhibition. Teachers can also give students some assignments that are outside of the classroom to have students write or speak.

Besides, healthy relationship between teachers and learners is also very significant. If a student cannot tolerate a teacher, it is very difficult for him or her to study the subject the teacher teaches. So in daily teaching, the teacher should care about the students, show great patience to the students. A heart full of mercy can help the students master the knowledge more easily. The teacher should have the ability to stand in the students' shoes. Healthy relationship between teachers and learners can reduce the students' anxiety, arouse their intention, correct their bad behaviors and thus to help them to learn in SLA in a correct way.

\section{Implication of Affective Factors in SLA on Studying}

\subsection{To Establish Self-Confidence}

Students should be confident, which is much easier said than done. Learners 
should have the idea that making mistakes is normal and necessary. It is inevitable to make mistakes while learning new things. People make mistakes and then learn a lesson from the mistakes. What is important is that people who make mistakes reflect on themselves. The same kind of mistakes can be avoided in this way. In addition, students can talk with their friends, especially those who have the same situation with them, like classmates. Empathy may be helpful for students who have low self-esteem to participate in the class activities. They may be enlightened or inspired by their classmates to communicate in the target language.

Moreover, students should know their own strong points and weak points clearly, and then set a goal which is not too difficult to accomplish. The sense of accomplishment can give people confidence to a large extent.

\subsection{To Develop Motivation}

Students may be under pressure from different courses and potential pressure form work. At present, the increasingly competitive labor market may give students a lot of pressure caused by employment. Sometimes, pressure can be transformed to motivation if students have a good attitude towards it.

Besides, goals can help students to build motivation to study. Students can also set short-term and long-term goals. Short-term goal should be related to specific task and activity in class, for example, to comprehend an article, or to memorize a short dialogue. While long-term goal should be based on social needs, for instance, to realize the Chinese dream of the great renewal of the Chinese nation.

Moreover, the students can pay attention to develop their own interest in the language, which is not only advantageous to promote themselves to learn, but also helpful to make them feel pleasant. Interest is the most helpful instructor.

\subsection{To Lower Anxiety}

Students can cooperate with classmates both in class and after class, which can help themselves to share knowledge with each other, help each other, and lower the anxiety and pressure while learning a new language. Students should have the awareness that no matter when confronting with difficult problems, it is much more helpful to work it together with other people.

Students can also resort to translation into native language to clarify a word or meaning. In addition, L2 learners shall try to learn to be tolerant with their own shortcomings during learning a second language. Making mistakes is a natural process for language learning. The process of making mistakes and correction helps you to succeed in second language learning.

\section{Conclusion}

In foreign language teaching, affective factors play significant roles. During the practice of teaching foreign language, the teacher can apply with different me- 
thods to design the class in a more relaxed and diversified way, so as to arouse the students' interest, ease their tension, and help them have the enthusiasm to learn language. Students themselves can also do some researches to learn the affective factors. Bearing those factors in mind, they can have the awareness to avoid the negative influences and exert the intuitive subjectivity to study.

It is a big challenge for the L2 teachers to lower the degree of the affective filter for the students. To meet this challenge, they need continuous studies and countless practices. Besides, teachers can also equip themselves with more pedagogical methodology and psychological knowledge, and make endless efforts to increase the students' self-esteem, lower their anxiety, arouse the their motivation, and enhance their learning efficiency.

\section{Conflicts of Interest}

The authors declare no conflicts of interest regarding the publication of this paper.

\section{References}

Arnold, J., \& Douglas, B. H. (2000). Affect in Language Learning. Beijing: Foreign Language Teaching and Research Publishing.

Deci, E. (1975). Intrinsic Motivation. New York, NY: Plenum Press. https://doi.org/10.1007/978-1-4613-4446-9

Douglas, B. H. (2014). Principles of Language and Teaching (6th ed.). White Plains, NY: Pearson Education.

Krashen, S. (1985). The Input Hypothesis: Issues and Implications. London: Longman.

Maslow, A. H. (1943). A Theory of Human Motivation. Psychological Review, 50, 370-396. https://doi.apa.org/doi/10.1037/h0054346

Rogers, C. R. (1950). A Current Formulation of Client-Centered Therapy. Social Service Review, 24, 442-450. https://doi.org/10.1086/638020

Rubio, F. (2007). Self-Esteem and Foreign Language Learning. Newcastle: Cambridge Scholars Publishing.

Stern, H. H. (1983). Fundamental Concepts of Language Teaching. Oxford: Oxford University Press.

$\mathrm{Wu}, \mathrm{Q}$. (2008). The Influence of Affective Factors in SLA on Foreign Languages Teaching. Journal of Xichang College Social Science Edition, 20, 147-149.

Yi, H. B. (2008). Individual Affective Factors in SLA and Foreign Language Teaching. Journal of Jixi University, 8, 94-95.

Zhang, X. P. (2011). The Implication of Affective Factors in Second Language Acquisition on Foreign Language Teaching. Journal of Jinan Vocational College, 6, 100-102. 